\title{
The 6-minute pegboard and ring test is correlated with upper extremity activity of daily living in chronic obstructive pulmonary disease
}

This article was published in the following Dove Press journal:

International Journal of COPD

22 July 2013

Number of times this article has been viewed

\author{
Kenichi Takeda' \\ Yuji Kawasaki² \\ Kazumasa Yoshida ${ }^{3}$ \\ Yoji Nishida ${ }^{3}$ \\ Tomoya Harada' \\ Kosuke Yamaguchi ${ }^{2}$ \\ Shizuka Ito' \\ Kiyoshi Hashimoto' \\ Shingo Matsumoto' \\ Akira Yamasaki \\ Tadashi Igishi' \\ Eiji Shimizu'
}

'Division of Medical Oncology and Molecular Respirology, Department of Multidisciplinary Internal Medicine, Tottori University, Yonago, Japan; ${ }^{2}$ Department of Regional Medicine, Faculty of Medicine, Tottori University, Yonago, Japan; ${ }^{3}$ Department of Rehabilitation Medicine, Yoka Hospital, Yabu, Japan
Correspondence: Kenichi Takeda Division of Medical Oncology and Molecular Respirology, Department of Multidisciplinary Internal Medicine, Tottori University, 86 Nishimachi, Yonago, 683-0862, Japan

$\mathrm{Tel}+8 \mathrm{I} 859386537$

Fax +8I 859386539

Email kentake724@gmail.com
Background: Upper-extremity exercise is for pulmonary rehabilitation. The 6-minute pegboard and ring test (6PBRT) was developed to evaluate arm exercise capacity in patients with chronic obstructive pulmonary disease (COPD). The purpose of this study was to characterize the 6PBRT and evaluate its relationship with upper-extremity activities of daily living (ADLs) in COPD patients.

Methods: Twenty outpatients with mild to very severe COPD underwent the 6PBRT and spirometry, and their maximal inspiratory and expiratory pressures and grip strength were measured. For the 6PBRT, subjects were asked to move as many rings as possible in 6 minutes, and the score was the number of moved rings during the 6-minute period. Upper-extremity ADLs were evaluated with the upper extremity activities subdomain of the modified Pulmonary Functional Status and Dyspnea Questionnaire. Upper-extremity ADLs were also measured objectively by using a wrist accelerometer every day for 1 week.

Results: There was a positive correlation between 6PBRT score and inspiratory capacity $(r=0.71, P<0.001)$, inspiratory capacity/total lung capacity predicted $(r=0.68, P<0.01)$, and forced vial capacity $(r=0.57, P<0.01)$. There was also a positive correlation between 6PBRT score and accelerometer count $(r=0.54, P<0.05)$ and a negative correlation between 6PBRT score and arm activity score $(\rho=-0.49, P<0.05)$.

Conclusion: The 6PBRT may be a predictive test to maintain and improve upper-extremity ADL during pulmonary rehabilitation in patients with COPD.

Keywords: pulmonary rehabilitation, inspiratory capacity, COPD, wrist accelerometer, modified Pulmonary Functional Status and Dyspnea Questionnaire

\section{Introduction}

For most patients with chronic obstructive pulmonary disease (COPD), exercise intolerance is the most distressing consequence of the disease. Exercise intolerance can be improved by training and rehabilitation, and these are frequently included in the treatment for patients with COPD. ${ }^{1-3}$ Previously, most pulmonary rehabilitation (PR) programs focused on exercising the lower extremities. However, upper-extremity exercise is increasingly recognized as an important component of PR. ${ }^{2,4}$ To evaluate PR of the upper extremities, exact measurement of the upper-extremity exercise capacity and physical activities of daily living (ADLs) is necessary.

The 6-minute pegboard and ring test (6PBRT) was developed by Celli et al ${ }^{5}$ to test patients with COPD. Zhan et $\mathrm{al}^{6}$ showed that the 6PBRT is a reliable method for the assessment of unsupported upper-extremity exercise in patients with COPD. However, the characteristics of 6PBRT measurements have not been fully inves- 
tigated. Furthermore, the exact relationship between the 6PBRT and upper-extremity ADL remains unclear. The purpose of this pilot study was to determine the characteristics of the 6PBRT and to evaluate the relationship between this test and upper-extremity ADL in patients with COPD.

\section{Methods}

Twenty patients with COPD were recruited from our outpatient clinics from January 2010 to August 2011. The diagnostic criteria for COPD were: a forced expiratory volume in 1 second $\left(\mathrm{FEV}_{1}\right)$; a forced vital capacity (FVC) ratio $<70 \%$; and a predicted $\mathrm{FEV}_{1}<80 \%$ after bronchodilator inhalation. All patients had clinical histories consistent with mild to very severe COPD (stage 1, four patients; stage 2, six patients; stage 3 , nine patients; and stage 4 , one patient), according to the Global Initiative for Chronic Obstructive Lung Disease classification. ${ }^{7}$ Patients in a clinically stable condition were included, whereas those with exacerbation, hospital admission in the preceding 3 months, unstable cardiovascular disease, or a rapidly declining clinical course were excluded. This study was approved by the Human Subjects Committee of the Tottori University. The aim of the study was fully explained to participants, and all gave informed consent.

Body height, body weight, pulmonary function, maximal inspiratory pressure $\left(\mathrm{PI}_{\max }\right)$, maximal expiratory pressure $\left(\mathrm{PE}_{\max }\right),{ }^{8,9}$ and grip strength were measured on the same day as the 6PBRT was performed. Spirometry was performed using a portable spirometer (DISCOM-21; CHEST MI, Inc, Tokyo, Japan) according to the American Thoracic Society guidelines. ${ }^{10}$ The predicted values for spirometric variables were calculated according to the Japanese Respiratory Society guidelines. ${ }^{11} \mathrm{PI}_{\max }$ and $\mathrm{PE}_{\max }$ were measured with a Vitalopower KH-101 (CHEST MI, Inc). PI ${ }_{\text {max }}$ was measured at residual volume, and $\mathrm{PE}_{\text {max }}$ was measured at total lung capacity (TLC). Grip strength was measured using a digital grip-strength meter (TKK5401; Takei Scientific Instruments Co, Ltd, Niigata City, Japan). The severity of breathlessness in daily life was evaluated within 1 month of performing the 6PBRT by using the Japanese version of the Medical Research Council dyspnea scale. ${ }^{13}$

The 6PBRT was performed according to the method of Zhan et al, ${ }^{6}$ with a slight modification. Briefly, subjects were asked to move as many rings (each ring weighed $50 \mathrm{~g}$; Zhan et al had used rings weighing half an ounce) as possible in 6 minutes, and the score was the number of rings moved during the 6-minute period. Pulse oxygen saturation was measured during the test by using a $\mathrm{SpO}_{2}$ monitor (WEC7201; Nihon Kohden Corporation, Tokyo, Japan) attached to the patient's ear lobe. Scores for dyspnea were evaluated using a modified Borg scale $(0-10)^{13}$ immediately after the test.

Upper-extremity ADLs were evaluated using a physical activity questionnaire and an accelerometer within 1 month of performing the 6PBRT. The Japanese version of the modified Pulmonary Functional Status and Dyspnea Questionnaire (PFSDQ-M) ${ }^{14,15}$ was used in this study. The PFSDQ-M comprises three domains: dyspnea with activity, fatigue with activity, and change in activity level. From the "change in activity level" domain, six upper extremity activity items were selected to subjectively evaluate activities using the upper extremities: (1) brushing hair; (2) raising arms above the head; (3) bathing; (4) washing hair; (5) putting on a shirt; and (6) preparing lunch. The patients reported changes in these items, assigning a score from $0-10$ for each activity as follows: 0 (no change: performs the activity as he/she always has); 1-3 (slight change); 4-6 (moderate change); 7-9 (extreme change); and 10 (no longer performs that activity). The response scores were then totaled.

In this study, upper extremity ADLs were also objectively quantified using a wrist accelerometer (Actiwatch $2^{\circledR}$; Philips Respironics Inc, Murrysville, PA, USA), which is an instrument sensitive to movement. The wrist accelerometer is $43 \times 23 \times 10 \mathrm{~mm}$ in size and weighs $16 \mathrm{~g}$; it records and stores the time and the intensity of movements. This device only has one recording mode, ie, activity counts. Activity counts are collected when the accelerometer detects motion over 1-minute epochs. When increased activity occurs in 1 epoch, the number of counts increases. The accelerometer was worn on the wrist of the nondominant hand, which was established when the patient was at the hospital, and activity counts were measured 24 hours a day for 7 consecutive days. The average activity counts were collected.

\section{Data analysis}

Statistical analyses were performed using GraphPad Prism 4 statistical software (GraphPad Software, Inc, San Diego, CA, USA). The results are expressed as the mean \pm standard deviation. Pearson product moment correlation coefficients were used to determine the correlation between 6PBRT scores and pulmonary function, $\mathrm{PI}_{\max }$, $\mathrm{PE}_{\max }$, grip strength, and Actiwatch $2^{\circledR}$ counts. Spearman 
rank correlation coefficients were used to determine the correlation between 6PBRT scores and PFSDQ-M subdomain scores. A $P$-value $<0.05$ was considered statistically significant.

\section{Results}

\section{Patient characteristics}

Patient characteristics are shown in Table 1. The 6PBRT was performed by all patients, and an average of $274 \pm 91$ rings was moved in 6 minutes (Table 2). The median PFSDQ-M subdomain score was 2 : eight of 20 patients scored 0 , three of 20 patients scored $>18$, and others scored $2-8$.

\section{Correlation between 6PBRT score and pulmonary function tests}

There was a positive correlation between 6PBRT score and inspiratory capacity (IC) $(r=0.71, P<0.001)$, IC/TLC predicted $(r=0.68, P<0.01)$, vital capacity $(\mathrm{VC})(r=0.52$, $P<0.05)$, and FVC $(r=0.57, P<0.01)$; however, there was no significant correlation between 6PBRT score and any other index of pulmonary function (Table 3).

Table I Subject characteristics

\begin{tabular}{|c|c|c|c|c|}
\hline Variables $(n=20)$ & & & & \\
\hline Males/females, $\mathrm{n}$ & $18 / 2$ & & & \\
\hline Age, years & $76(59-85)$ & & & \\
\hline $\mathrm{BMI}, \mathrm{kg} / \mathrm{m}^{2}$ & $20.0 \pm 3.3$ & & & \\
\hline GOLD stage: $(n)$ & I: $4 \quad 2: 6$ & 3: 9 & 4: I & \\
\hline MRC dyspnea scale score: (n) & $0: 3 \quad$ I: I & 2: 5 & $3: 8$ & 4: 3 \\
\hline VC, L & $2.99 \pm 0.7$ & & & \\
\hline VC predicted, \% & $93.3 \pm 9.1$ & & & \\
\hline IC, L & $\mathrm{I} .83 \pm 0.5$ & & & \\
\hline IC/TLC predicted, \% & $30 \pm 8.0$ & & & \\
\hline FVC, L & $2.80 \pm 0.7$ & & & \\
\hline FVC predicted, \% & $88.2 \pm 17.5$ & & & \\
\hline $\mathrm{FEV}_{1}, \mathrm{~L}$ & $1.31 \pm 0.6$ & & & \\
\hline FEV , predicted, \% & $51.0 \pm 20.7$ & & & \\
\hline $\mathrm{FEV}_{1} / \mathrm{FVC}$ & $45.7 \pm 12.7$ & & & \\
\hline $\mathrm{PI}_{\max }, \mathrm{cmH}_{2} \mathrm{O}$ & $48.5 \pm 18.6$ & & & \\
\hline $\mathrm{PI}_{\max }$ predicted, $\%$ & $77.9 \pm 30.5$ & & & \\
\hline $\mathrm{PE}_{\max }, \mathrm{cmH}_{2} \mathrm{O}$ & $77.4 \pm 33.5$ & & & \\
\hline $\mathrm{PE}_{\max }$ predicted, \% & $88.1 \pm 38.3$ & & & \\
\hline Grip strength, kg & $26.2 \pm 5.6$ & & & \\
\hline
\end{tabular}

Note: The values shown represent the mean \pm standard deviation or median (range), unless otherwise indicated.

Abbreviations: n, number; BMI, body mass index; GOLD, Global initiative for chronic Obstructive Lung Disease; MRC, Medical Research Council; VC, vital capacity; IC, inspiratory capacity; TLC, total lung capacity; FVC, forced vital capacity; $\mathrm{FEV}_{1}$, forced expiratory volume in I second; $\mathrm{PI}_{\text {max }}$, maximal inspiratory pressure; $\mathrm{PE}_{\text {max }}$, maximal expiratory pressure; $L$, lung.
Table 2 6PBRT score and upper extremity physical activity

\begin{tabular}{lll}
\hline 6PBRT score & \multicolumn{2}{l}{$\mathbf{2 7 4} \pm \mathbf{9 1}$} \\
\cline { 2 - 3 } & Before the test & After the test \\
\hline $\mathrm{SpO}_{2}$ & $96(93-98)$ & $95(81-99)$ \\
Borg scale & - & $4(0.5-7.0)$ \\
Upper extremity physical activities & \\
\multicolumn{2}{l}{ Actiwatch $2^{\circledR}$ counts } & $193 \times 10^{3} \pm 102 \times 10^{3}$ \\
PFSDQ-M subdomain score & $2(0-29)$ & \\
\hline
\end{tabular}

Note: The values shown represent the mean \pm standard deviation or median (range).

Abbreviations: 6PBRT, 6-minute pegboard and ring test; PFSDQ-M, modified Pulmonary Functional Status and Dyspnea Questionnaire.

\section{Correlation between 6PBRT score and upper-extremity physical ADLs}

There was a negative correlation between 6PBRT score and PFSDQ-M subdomain scores $(\rho=-0.49, P<0.05)$ and a positive correlation between 6 PBRT score and Actiwatch $2^{\circledR}$ counts $(r=0.54, P<0.05)$ (Figure 1 and Table 4$)$.

\section{Discussion}

Upper extremity training is now recognized as an important component in the PR of patients with COPD. ${ }^{4}$ However, there are no specific recommendations on how to objectively measure upper-extremity exercise capacity or ADL. The objectives of this pilot study were to determine the characteristics of the 6PBRT via pulmonary function tests and to evaluate whether the 6PBRT can be used to measure upper-extremity ADL in patients with COPD.

Table 3 Correlation between 6PBRT score and pulmonary function, $\mathrm{PI}_{\max }, \mathrm{PE}_{\max }$, and grip strength

\begin{tabular}{|c|c|c|}
\hline & $\mathbf{r}^{*}$ & $P$-value \\
\hline VC, L & 0.52 & $<0.05$ \\
\hline VC predicted, \% & 0.38 & NS \\
\hline IC, L & 0.71 & $<0.001$ \\
\hline IC/TLC predicted, \% & 0.68 & $<0.01$ \\
\hline FVC, L & 0.57 & $<0.01$ \\
\hline FVC predicted, \% & 0.43 & NS \\
\hline $\mathrm{FEV}_{1}, \mathrm{~L}$ & 0.39 & NS \\
\hline FEV , predicted, \% & 0.31 & NS \\
\hline $\mathrm{FEV}_{1} / \mathrm{FVC}$ & 0.14 & NS \\
\hline $\mathrm{PI}_{\max }, \mathrm{cmH}_{2} \mathrm{O}$ & 0.36 & NS \\
\hline $\mathrm{PI}_{\max }$ predicted, \% & 0.31 & NS \\
\hline $\mathrm{PE}_{\max }, \mathrm{cmH}_{2} \mathrm{O}$ & 0.16 & NS \\
\hline $\mathrm{PE}_{\max }$ predicted, $\%$ & 0.21 & NS \\
\hline Grip strength, kg & 0.24 & NS \\
\hline
\end{tabular}

Note: *Pearson's product moment correlation coefficient.

Abbreviations: 6PBRT, 6-minute pegboard and ring test; $\mathrm{Pl}_{\max }$, maximal inspiratory pressure; $\mathrm{PE}_{\max }$, maximal expiratory pressure; $\mathrm{VC}$, vital capacity; NS, not significant; IC, inspiratory capacity; TLC, total lung capacity; FVC, forced vital capacity; $\mathrm{FEV}_{\text {, }}$, forced expiratory volume in I second; L, lung. 

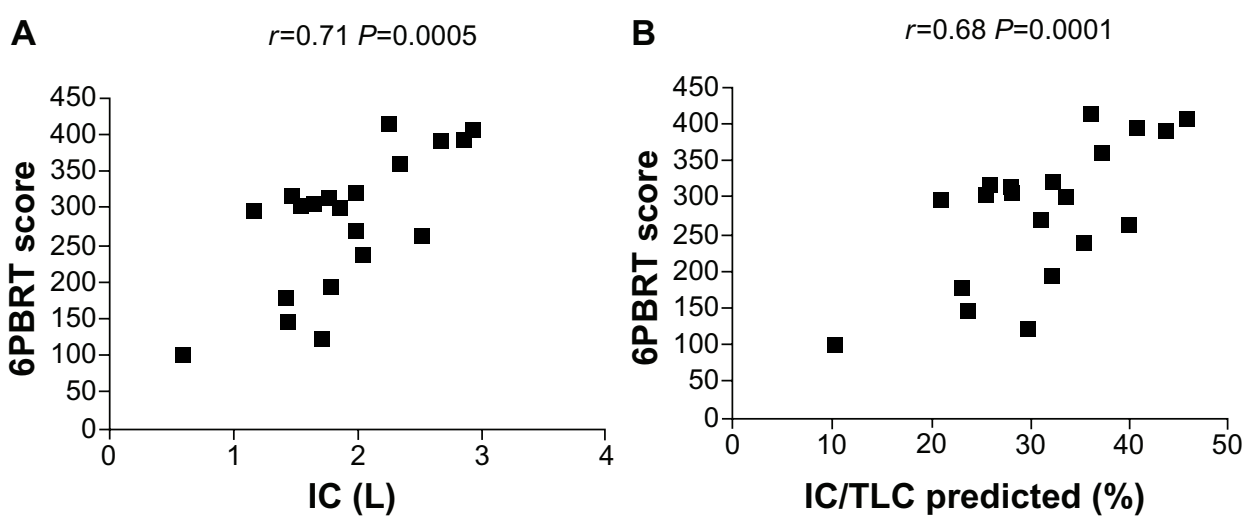

Figure I Correlation of 6PBRT score with inspiratory capacity and with inspiratory capacity/total lung capacity predicted.

Note: (A) The correlation between 6PBRT and IC $(0.71)$ was stasticially significant at $P<0.0005$. (B) The correlation between 6 PBRT and IC/TLC predicted $(0.68)$ was statistically significant at $P<0.00 \mathrm{I}$.

Abbreviations: 6PBRT, 6-minute pegboard and ring test; IC, inspiratory capacity; TLC, total lung capacity.

Significant relationships between 6PBRT score and VC, FVC, IC, and IC/TLC predicted (\%) were found in our study. During the 6PBRT, patients raised their hands to shoulder level or higher to move the rings, and this arm elevation position is similar to unsupported upperextremity exercise. Unsupported upper-extremity elevation increases functional residual capacity. ${ }^{16-18}$ This is likely due to passive stretching of the thoracic muscles and expansion of the rib cage, which imposes a greater burden that must be overcome by the diaphragm. Therefore, during unsupported upper extremity exercise, VC and IC decrease significantly ${ }^{18}$ and ventilation increases, which is associated with dynamic hyperinflation in patients with COPD. ${ }^{11}$ On the basis of these data, we speculate that in patients with intrinsically low IC, a further decrease in IC was caused by arm elevation during the 6PBRT, which led to a reduction in arm exercise capacity (as measured by the 6PBRT score), possibly through severe dynamic hyperinflation. Therefore, patients with low IC may have low upper-extremity exercise capacities.

In this study, upper-extremity ADLs in patients with COPD were evaluated using two methods, the PFSDQ-M (a questionnaire on upper-extremity activities subdomain)

Table 4 Correlation of 6PBRT score and upper extremity physical activity

\begin{tabular}{lll}
\hline & $\rho(\boldsymbol{r})$ & $P$-value \\
\hline PFSDQ-M subdomain score & $-0.49 *$ & $<0.05$ \\
Actiwatch $2^{\circledR}$ counts & $0.54^{\dagger}$ & $<0.05$ \\
\hline
\end{tabular}

Notes: *Spearman's rank correlation coefficient ( $\rho$ ); 'Pearson's product moment correlation coefficient $(r)$.

Abbreviations: 6PBRT, 6-minute pegboard and ring test; PFSDQ-M, modified Pulmonary Functional Status and Dyspnea Questionnaire. and the wrist accelerometer (Actiwatch $2^{\circledR}$ ), to objectively quantify the activities. The 6PBRT score had a negative correlation with the PFSDQ-M subdomain and a positive correlation with Actiwatch $2^{\circledR}$ counts. Because there were significant relationships between 6PBRT score and upper extremity function as measured by both the PFSDQ-M and Actiwatch $2^{\circledR}$ counts, the 6 PBRT is considered valuable and relevant for assessing upper-extremity ADLs. The 6PBRT can be a predictive marker of upper-extremity ADLs in patients with COPD.

Our study had some limitations. First, whether the Actiwatch $2^{\circledR}$ can accurately record daily upper-extremity activities has not been studied; therefore, the Actiwatch $2^{\circledR}$ counts need to be balanced against the activity counts measured with the more precise body motion accelerometer. Second, the sample size was small; thus, additional large-scale investigations are needed to verify our findings. Third, the full PFSDQ-M can evaluate other domains such as dyspnea and fatigue; however, this study was focused only on change in upper-extremity activity level, because this study mainly focuses on upper-extremity ADLs.

\section{Conclusion}

Our data showed that there were clear correlations between 6PBRT score and IC, IC/TLC predicted, and upper-extremity ADLs in patients with COPD. When considering PR to maintain or improve physical activities in patients with COPD, the 6PBRT can be used as a reference index or potential test of upper-extremity ADLs.

\section{Disclosure}

The authors report no conflicts of interest in this work. 


\section{References}

1. Casaburi R, Patessio A, Ioli F, Zanaboni S, Donner CF, Wasserman K. Reductions in exercise lactic acidosis and ventilation as a result of exercise training in patients with obstructive lung disease. Am Rev Respir Dis. 1991;143(1):9-18.

2. [No authors listed]. Pulmonary rehabilitation: joint ACCP/AACVPR evidence-based guidelines. ACCP/AACVPR Pulmonary Rehabilitation Guidelines Panel. American College of Chest Physicians. American Association of Cardiovascular and Pulmonary Rehabilitation. Chest. 1997;112(5):1363-1396.

3. Cyarto EV, Moorhead GE, Brown WJ. Updating the evidence relating to physical activity intervention studies in older people. J Sci Med Sport. 2004;7(Suppl 1):30-38.

4. Janaudis-Ferreira T, Beauchamp MK, Goldstein RS, Brooks D. How should we measure arm exercise capacity in patients with COPD? A systematic review. Chest. 2012;141(1):111-120.

5. Celli BR, Rassulo J, Make BJ. Dyssynchronous breathing during arm but not leg exercise in patients with chronic airflow obstruction. $N$ Engl J Med. 1986;314(23):1485-1490.

6. Zhan S, Cerny FJ, Gibbons WJ, Mador MJ, Wu YW. Development of an unsupported arm exercise test in patients with chronic obstructive pulmonary disease. J Cardiopulm Rehabil. 2006;26(3):180-187; discussion 188-190.

7. Global Initiative for Chronic Obstructive Lung Disease. Documents: global strategy for diagnosis, management, and prevention of COPD [webpage on the Internet]. Global Initiative for Chronic Obstructive Lung Disease; 2013 [updated Feb 2013]. Available from: http://www. goldcopd.org/guidelines-global-strategy-for-diagnosis-management. html. Accessed June 9, 2013.

8. Rochester DF, Arora NS. Respiratory muscle failure. Med Clin North Am. 1983;67(3):573-597.

9. American Thoracic Society/European Respiratory Society. ATS/ERS statement on respiratory muscle testing. Am J Respir Crit Care Med. 2002;166(4):518-624.
10. [No authors listed]. Standardization of spirometry, 1994 update. American Thoracic Society. Am J Respir Crit Care Med. 1995;152(3): 1107-1136.

11. Tamura G, Aizawa H, Nagai A, et al. Nihonjin niokeru Shouni to seijin kyoutuu no kokyuukinoukennsayosokushiki. [Common prediction equations of respiratory function tests from children to adults in Japan]. Nihon Kokyuki Gakkai Zasshi.2007:45:526-542.

12. Fletcher CM, Elmes PC, Fairbairn AS, et al. The significance of respiratory symptoms and the diagnosis of chronic bronchitis in a working population. Br Med J. 1959; 2:257-266.

13. Borg GA. Psychophysical bases of perceived exertion. Med Sci Sports Exerc. 1982;14(5):377-381.

14. Lareau SC, Meek PM, Roos PJ. Development and testing of the modified version of the pulmonary functional status and dyspnea questionnaire (PFSDQ-M). Heart Lung. 1998;27(3):159-168.

15. Kojima S, Ando M, Okazawa M, Sakakibara H, Hashimoto S, Nakajima S. Kokyuukishikkan tokuiteki kinoujoutai ni kansuru shakudo no nihongoban no kaihatsu. [Development of a Japanese version of the modified questionnaire on the pulmonary functional status and dyspnea]. Nihon Kokyuki Gakkai Zasshi. 2004;42(6):486-490. Japanese.

16. McKeough ZJ, Alison JA, Bye PT. Arm positioning alters lung volumes in subjects with COPD and healthy subjects. Aust J Physiother 2003;49(2):133-137.

17. Martinez FJ, Couser JI, Celli BR. Respiratory response to arm elevation in patients with chronic airflow obstruction. Am Rev Respir Dis. 1991;143(3):476-480.

18. Dolmage TE, Maestro L, Avendano MA, Goldstein RS. The ventilatory response to arm elevation of patients with chronic obstructive pulmonary disease. Chest. 1993;104(4):1097-1100.
International Journal of COPD

\section{Publish your work in this journal}

The International Journal of COPD is an international, peer-reviewed journal of therapeutics and pharmacology focusing on concise rapid reporting of clinical studies and reviews in COPD. Special focus is given to the pathophysiological processes underlying the disease, intervention programs, patient focused education, and self management protocols.

\section{Dovepress}

This journal is indexed on PubMed Central, MedLine and CAS. The manuscript management system is completely online and includes a very quick and fair peer-review system, which is all easy to use. Visit http://www.dovepress.com/testimonials.php to read real quotes from published authors. 